1 Papadopoulos VD, Nolan DJ. Carcinoma of the small intestine. Clin Radiol 36: 409-13.

2 Koehler R. Small bowel neoplasms (lymphoma) In: PC Freeney, GW Stevenson, eds. Alimentary tract radiology, Vth edn, 1994; pp 634-9.
3 Marshack RH, Khilnani MT, Eliasoph J, Wolf BS. Metastatic carcinoma of the small bowel. $A \mathcal{F} R$ 1965; 94, 385-94.

4 Beckley DE. Alimentary tract metastases from malignant melanoma. Clin Radiol 1974; 25: 385-9.

\title{
Sudden weakness in a young Chinese man
}

\author{
Venkat RR Kodali, Ben Jeffcote, Roy B Clague
}

A 31-year-old man from mainland China presented with sudden onset weakness of limbs of eight hours duration. He had woken up from bed with weakness. He was not on any medication; both parents and brother are healthy. On examination he had motor weakness with diminished deep jerks. Non-tender hepatomegaly was present.

Investigations revealed normal blood counts, urea, creatinine, glucose and electrolytes were normal, creatine kinase $1105 \mathrm{U} / 1$ (reference range: 10-195), alanine transaminase $68 \mathrm{U} / 1$ (540), aspartate transaminase $49 \mathrm{U} / 1(6-37)$, alkaline phosphatase $180 \mathrm{U} / 1(98-279)$, glutamyl transferase $128 \mathrm{U} / 1(10-50)$, plasma viscosity $1.57 \mathrm{mPas}$ at $25^{\circ} \mathrm{C}(1.50-1.72)$. Electrocardiograms were normal and chest X-ray was clear. Peak flow was $560 \mathrm{l} / \mathrm{min}$.

He recovered naturally and, while awaiting other results, was discharged. He was re-admitted within a week with hypokalemia of $1.8 \mathrm{mmol} / \mathrm{l}(3.5-5.5)$. The outstanding investigations were by then available. Free thyroxine $65.6 \mathrm{pmol} / \mathrm{l}(9-24)$, thyroid-stimulating hormone (TSH) $<0.05 \mathrm{mU} / 1(0.49-4.67)$, free tri-iodothyronine $24 \mathrm{pmol} / 1$ (4-8.3). Antiparietal cell antibodies were positive, thyroid autoantibodies were not detected, ds-DNA, antinuclear antibodies, antismooth muscle, mitochondrial and extractable nuclear antigen, and Jo1 were negative. Muscle biopsy did not show significant abnormalities. Electromyography and nerve conduction studies were normal. By this time creatine kinase levels had normalised. Hepatitis B surface antigen and anti- $\mathrm{Hb} \mathrm{E}$ were positive and $\mathrm{Hb} \mathrm{E}$ antigen was negative.

Department of Medicine, Noble's Isle of Man Hospital, Douglas, Isle of Man IM1 4QA, UK

VRR Kodali

B Jeffcote RB Clague

Accepted 16 April 1997

\section{Questions}

1 What is your diagnosis?

2 How would you treat the weakness and what complications may arise from treatment?

3 Will the patient be prone to further paroxysmal weakness?

4 What other history would you consider important in this type of hepatitis and what will you inform the patient? 
Answers

QUESTION 1

Thyrotoxic periodic paralysis together with hepatitis $B$ at low infective risk.

\section{QUESTION 2}

The patient was managed with parenteral potassium supplements with bedside monitoring. He was started on carbimazole and developed a rash which is a common adverse effect. The medication was changed to propylthiouracil which he tolerated well. Thyroid function tests after three weeks were: total free thyroxine $22 \mathrm{pmol} / 1$ and TSH $<0.05 \mathrm{mU} / 1$. The other complications of carbimazole include sore throat, mouth ulcers due to bone marrow suppression, and arthralgias. Patients should be informed of these side-effects; blood counts must be done and carbimazole stopped if agranulocytosis is noticed. These antithyroid drugs act by inhibiting oxidation and creating an intrathyroidal iodine depletion. Our patient is awaiting radioiodine therapy.

\section{QUESTION 3}

The episodes of weakness will cease once an euthyroid state is established. Meanwhile, short-term use of beta-blockers are effective. Avoiding strenuous exercise and avoiding high carbohydrate diets will help.

\section{QUESTION 4}

The condition suggests a possible history of parenteral drug use, tattoos and/or sexual activity. Our patient had not received any blood or blood products. The abnormal liver function tests are due to hepatitis. He should be informed that his blood and secretions are infectious to others and of the risks of chronic liver failure and hepatocellular carcinoma.

\section{Discussion}

Thyrotoxic periodic paralysis is a common cause of weakness in young people of Chinese ethnic origin and it rarely occurs in Caucasians. Interestingly, the subjects more often do not manifest the classical picture of thyrotoxicosis, which can be misleading. Thyrotoxic periodic paralysis classically starts in the early

1 Ko GTC, Chow CC, Yeung VTF, Chan HHL, Li JKY, Cockram CS. Thyrotoxic periodic paralysis in a Chinese population. Of Med 1996; 89: 463-8.

2 McFadzean AJS, Yeung R. Periodic paralysis complicating thyrotoxicosis in Chinese. BMF 1967; 1: 451-5.

3 Fong TL, McHutchison JG, Reynolds TB. Hyperthyroidism and hepatic dysfunction: a case series analysis. $\mathcal{f}$ Clin Gastroenterol 1992; 14: 240-4

4 Szeto CC, Chow CC, Ko GTC, Li KY, Yeung VTF, Cockram CS. A patient with Graves' disease, thrombocytopenia and chronic hepatitis B. Postgrad Med $\mathcal{F}$ 1997; 73: $39-48$.

Thyrotoxic periodic paralysis
- sudden onset weakness
- common in young Chinese men
- apparent lack of clinical signs of thyrotoxicosis
- treatment: correction of hypokalaemia,
antithyroid drugs, beta-blockers, avoiding high
carbohydrate diets and strenuous activity
- attacks cease with euthyroid status

Box 1

morning hours, usually following a day of strenuous activity. Speech is usually spared and weakness involves limbs. Almost all cases occur sporadically (95\%) and in a series reported from Hong Kong, the subjects did not have a familial history of periodic paralysis. ${ }^{1}$

Male preponderance is a recognised characteristic. $^{2}$ Thyrotoxic periodic paralysis is indistinguishable from idiopathic familial periodic paralysis but has a higher propensity for arrhythmia, cardiac arrest and respiratory failure. Hyperthyroidism per se can elevate liver enzymes. ${ }^{3}$ Hepatitis B may flare-up with thyrotoxicosis and achieving the euthyroid status may help remission. ${ }^{4}$

In thyrotoxic periodic paralysis, hypokalaemia develops due to an intracellular shift of potassium and not its depletion. A recent study identified increased $\mathrm{Na}^{+}, \mathrm{K}^{+}$-ATPase activity in platelets in thyrotoxic patients with or without periodic paralysis. ${ }^{5}$ In vivo sodium pump activity in muscle, kidney and liver is also increased in thyrotoxicosis and this activity is restored with treatment. ${ }^{6} \mathrm{~A}$ recent case report of a patient with Graves' disease and hepatitis, ${ }^{4}$ and our subject with hepatitis $B$, parietal cell antibodies and thyrotoxicosis, indicate the need for further studies to look for any immunological links in hepatitis B.

\section{Final diagnosis}

Thyrotoxic periodic paralysis.

Keywords: thyrotoxic periodic paralysis, hepatitis B, Chinese

5 Chan A, Shinde R, Chan CC, Cockram CS, Swaminathan $\mathrm{R}$. In vivo and in vitro sodium pump activity in subjects with thyrotoxic periodic paralysis. BMF 1991; 303: 1096-9.

6 Layzer RB. Periodic paralysis and the sodium-potassium pump. Ann Neurol 1982; 11: 547-52. 